\title{
INTRODUCTION TO THE NASH ISSUE
}

\author{
SUSAN FRIEDLANDER
}

This issue of the Bulletin of the American Mathematical Society contains four survey articles related to the tremendous influence of the the mathematical ideas of John Forbes Nash Jr. In 2015 I invited Misha Gromov to write an article for the Bulletin surveying his own work and its implications. About six months later I received a manuscript from Misha which, with characteristic modesty, he devoted to a presentation of the Nash isometric embedding theorems and the rich trove of mathematics that follows from these theorems of John Nash. I then solicited three more articles from authors who spoke at the Princeton celebration in October 2015 of the lives of John and Alicia Nash. The couple was tragically killed in a New Jersey traffic accident as they returned to Princeton from Oslo where John Nash received the Abel Prize "for striking and seminal contributions to nonlinear partial differential equations and its applications to geometric analysis". The four articles in this "Nash" issue of the Bulletin discuss the work of Nash on the topics cited in the Abel Prize and also the implications of his ideas for algebraic geometry. An additional remarkable strand, not discussed in these articles, follows from Nash's $1950 \mathrm{PhD}$ thesis in which he introduced what is now called a "Nash equilibrium". This revolutionized areas of economics and led to Nash's Nobel Memorial Prize in Economic Sciences in 1994.

The four survey articles in the "Nash" issue discuss original mathematical contributions by Nash which broke new ground in crucial ways.

- Misha Gromov outlines the boundaries of our knowledge and indicates directions to be pursued concerning the Nash isometric embedding theorems.

- Camillo de Lellis and László Székelyhidi Jr. present "an analyst's point of view" on the Nash-Kuiper theorem and highlight the close connection to turbulence.

- Sergiu Klainerman focuses on the enormous impact on the modern theory of partial differential equations of three articles by John Nash.

- János Kollár surveys Nash's contributions to algebraic geometry, focusing on the topology of real algebraic sets and on arc spaces of singularities.

All this seminal work by Nash was published in a very small number of papers whose Mathematical Reviews are reprinted in the Mathematical Perspectives section of this issue.

The survey articles illustrate the striking breadth and creativity of Nash. His work occurred in a dramatically short period of less than a decade when he was at the height of his mathematical power between his $\mathrm{PhD}$ in 1950 and the onset of mental disorders in 1959. For three decades he suffered from the troubles and delusions of schizophrenia. He ceased to write mathematics, but rather in his role as "the phantom of Fine Hall" he wrote unintelligible symbols on the blackboards in 
the basement of the Princeton mathematics department. Eventually, and somewhat unusually, he recovered from schizophrenia, and by the 1990s he could think about mathematics and appreciate the importance of his early work. Ultimately the academic world, which had been using the name "Nash" associated with numerous essential tools of mathematics and economics, became aware of the existence of the man whose genius created those tools and gave him due recognition and honor.

The president of Princeton University, Christopher Eisgruber, wrote after their tragic death, "The world felt a personal connection to John and Alicia Nash, and people around the globe felt a personal loss when they died so suddenly. Through the magnificence of John's achievements, their shared courage in the face of his illness, and the many unexpected turns in their remarkable lives, John and Alicia embodied for millions of people both the exhilaration of human aspiration and the sorrow of human tragedy."

The Princeton mathematics department is well known for the high quality of its students. The year 1950 was exceptional even by Princeton's standards with a brilliant trio of students all called John: John Nash, who was finishing as a graduate student; John Tate, who had just arrived as a graduate student; and John Milnor, who was rapidly morphing from a stellar undergraduate to a graduate student to a faculty member. All three swiftly became famous and went on to become some of the most influential mathematicians of the 20th century. In recent years all three have been awarded the Abel Prize: John Tate in 2010, John Milnor in 2011, and John Nash in 2015. The editors of the Bulletin of the American Mathematical Society are delighted to produce special issues concerning the work and influence of all three of these brilliant mathematicians. The issue in October 2015 is centered around the seminal contributions to topology of John Milnor, and it contains his article "Topology through the centuries: low dimensional manifolds". This present issue, appearing in April 2017, celebrates the exceptional significance of the work of John Nash. We are currently compiling material for the "Tate" issue highlighting his vast and lasting impact on number theory, and we anticipate this issue will appear in 2018.

Many details concerning the life of John Nash can be found in the excellent biography by Sylvia Nasar, A Beautiful Mind (Simon and Schuster, 1998), and in The Essential John Nash, edited by Harold Kuhn and Sylvia Nasar (Princeton University Press, 2002).

Department of Mathematics, University of Southern California, los Angeles, CalIFORNIA, 90089

E-mail address: susanfri@usc.edu 